\title{
Comparative Study of Dipteran Species Diversity and Their Succession on Rabbit Carrion in Two Different Mangrove Areas of Peninsular Malaysia
}

\author{
Wahizatul Afzan Azmi and S. P. Lim \\ Department of Biological Sciences, Faculty of Science \& Technology, Universiti Malaysia Terengganu, \\ 21030 Kuala Terengganu, Terengganu, Malaysia \\ Correspondence should be addressed to Wahizatul Afzan Azmi; wahizatul@umt.edu.my
}

Received 24 April 2013; Revised 17 July 2013; Accepted 17 July 2013

Academic Editor: Francisco de Sousa Ramalho

Copyright (C) 2013 W. A. Azmi and S. P. Lim. This is an open access article distributed under the Creative Commons Attribution License, which permits unrestricted use, distribution, and reproduction in any medium, provided the original work is properly cited.

A study on dipteran utility in assisting investigation of unattended deaths was carried out in mangrove areas of Kuala Terengganu, Terengganu, and Masai, Johor, in Peninsular Malaysia by using rabbit carrions as the model. The aim of this study was to determine the dipteran species diversity and their succession over the decomposition period of the rabbit carrions. A total of 229 individuals belonging to 11 species from six families of Diptera were successfully identified from both study sites in October and December 2007. Chrysomya megacephala, C. rufifacies, and Hydrotaea sp. were found to be the most abundant species recorded in this study. More species were collected from Masai with 10 species compared to Kuala Terengganu with nine species. Ecological indices (Shannon Wiener Index, Margalef Index, and Evenness Index) showed that Masai scored higher diversity, richness, and evenness values than Kuala Terengganu. However, Mann-Whitney $U$ test did not show significant difference among the individuals represented at each study site $(P>0.05)$. Calliphoridae predominated in the carrion during the fresh, bloat, and active decay stages of decomposition. Dipteran development was documented to be meteorologically dependent whereby; low temperature and high rainfall inhibit their colonization. Data collected in this study can hopefully serve as the basis for future estimates of the postmortem interval (PMI) particularly in mangrove area of tropical regions.

\section{Introduction}

Flies (Diptera) are among the most omnipresent and widely distributed insects. Their close association with humans has led them to be recognized as unpleasant and disturbing creatures, and certainly some flies are responsible for millions of illnesses and deaths among human populations. Yet flies are also among the key components in most ecosystems and are advantageous in many ways [1]. Because many flies develop from earlier to later stages of a life cycle in the bodies of dead vertebrates, and because several species leave behind a heavily hardened puparial case that may endure for centuries, flies are the most significant organisms for forensic study. They are especially valuable in determining the age of corpse from duration of a few hours to a few years [2].

Forensic entomology makes use of information derived from either the succession of arthropods on human corpses or animal carcasses or the temperature-dependent development of insects (primarily flies) to estimate the time elapsed since death, or postmortem interval (PMI), estimate of the time between death and corpse discovery [3]. It is important to know how long it takes for the insect to arrive on a corpse, the stage of decay to which it is attracted, its life cycle and its rate of development [4]. When a body is found or a crime scene is investigated, the presence of insects, or lack thereof, can provide many clues as to what actually happened. Time of death can be ascertained and many clues about the cause of death or events just prior to death can be determined based on insect behaviour and interaction with a corpse. However, after three days, insect evidence is often the most accurate and sometimes the only method of determining elapsed time since death [5]. The time of death is a critical piece of information for investigators attempting to understand the cause of suspicious deaths [6]. 
In Malaysia, most of the studies reported the forensically important entomological specimens received from hospitals, police, and other agencies throughout Malaysia (e.g., [7, 8]). Lee and Marzuki [9] studied arthropods succession on monkey carcasses either fully exposed or partially buried near the fringes of tropical forest. Omar et al. [10] made observation on arthropods on monkey carrion at a rubber tree plantation in Malaysia. However, very limited study has been carried out to investigate the diversity of necrophagous insects in mangrove areas. The mangroves forests in Malaysia are unique ecosystems which have a great variety of mangrove species. Such areas are commonly subject to extensive sedimentation, which provides a diverse range of substrate types and nutrient levels, which in turn are favorable for mangrove growth [11]. Thus, diverse of insects such as flies, ants, beetles, wasp, mosquitoes, and butterflies and other insects occupy this ecosystem as their habitat.

Therefore, the main objectives of this study were (1) to identify the dipterans which occurred on the rabbit carrions in two different mangrove areas which located in the Kuala Terengganu, Terengganu, and in Masai, Johor, and (2) to investigate the dipteran succession pattern as a basis for future estimates of the PMI. The two mangrove areas representing different dominant species of mangroves were selected in order to investigate the factors that influence the dipteran diversity and succession in different part of peninsular Malaysia.

\section{Materials and Methods}

2.1. Study Sites. The study was conducted in two different mangrove areas which were located in Kuala Terengganu, Terengganu $\left(05^{\circ} 24^{\prime} 35.89^{\prime \prime} \mathrm{N} ; 103^{\circ} 05^{\prime} 28.71^{\prime \prime} \mathrm{E}\right)$, which represents the east coast and in Masai, Johor $\left(01^{\circ} 28^{\prime} 52.30^{\prime \prime} \mathrm{N}\right.$; $103^{\circ} 53^{\prime} 06.68^{\prime \prime} \mathrm{E}$ ), which represents the southern part of Peninsular Malaysia. Mangroves in Kuala Terengganu are more exposed to the South China Sea and has more sandy substrate compared to mudflats in Masai which is more shady and protected from the waves of sea. Mangrove area at Kuala Terengganu is less developed compared to Masai. Masai is very accessible and is located beside highway roads; construction activities are also held nearby the study site. In contrast, Kuala Terengganu mangrove area is still in a more pristine condition, reserved for research activities and less perturbed with human activities, thus minimizing human interference.

2.2. Carrion. Four rabbits (Oryctolagus cuniculus, L.), each weighing about $1.3 \mathrm{~kg}$, were used and studied for 14 days in this study. Two rabbits were slaughtered and placed in Kuala Terengganu mangrove area from 5 to 19 October 2007, while another two rabbits were studied in Masai from 8 to 22 December 2007. Immediately after death, the rabbits were placed in round metal cages $(40 \mathrm{~cm} \times 20 \mathrm{~cm})$ made with $1 \mathrm{~cm}$ wire meshing. This allowed access to the carrions by insects while prevening disturbances by vertebrate scavengers. The carrions were photographed daily. They were left under shady trees and the time was recorded. Samplings were taken twice a day, at 10 am and $5 \mathrm{pm}$.
2.3. Dipteran Sample Collection. Dipterans collected from different parts of the body were separated into different vials. Each vial and container was labelled with area of the body or soil where it was removed, date and time of collection, and stage of the insects when collected. A duplicate label was affixed to the exterior of the vial. Adults from the corpse were collected using a hand net. The captured flies were then killed immediately by placing them in the killing jar with cotton soaked in $70 \%$ of ethanol. Upon reaching the lab, the adult flies were pinned and the species were determined. Samples of 20-35 larvae were collected at the first appearance of instars and at subsequent of $12 \mathrm{~h}$ intervals with jeweler forceps from different areas (such as oral cavities, stomach, and anus cavities) and placed in glass vials. Half of the larvae samples were killed in hot water and then placed in appropriately labelled bottles containing 70\% ethanol [12]. These techniques prevent discoloration and shrinkage that will occur if living maggots are placed directly into common preservative solutions such as ethanol and formaldehyde. Shrinkage would make the maggots appear younger than they actually are. These specimens represent the "biological clock" to determine the PMI. This clock is started with the invasion of the insects and is stopped by the collection and preservation of insects from the carrion. Each development stage of each insect collected from the body represents a distinct interval of time on that clock. To determine the interval represented, each sample must be fixed in time and development by killing and preserving the specimens [13]. Another half of the larvae samples were placed on chicken liver and reared to the adult stage for positive taxonomic identification [12]. Labels for the collected samples contained information of date, time, location, sample number, and a description of visual observations and notations of the scene briefly. Sampled collections were repeated every 12 hours until the carrion was reduced to a skeleton and no more apparent insects occurred [14].

2.4. Identification. The identification of the species was done through the mounting process of larvae according to the pictorial key by Stojanovish et al. [15] and Seago [16]. The species was determined by comparing morphological features like the presence of an interior apical sklerite, shape, and colouration of the structures. As for the adult flies, morphological aspects from the pictorial key according to Jason and James [4], Wallman [17], Scott and Borom [18], and Dodge [19] were used.

2.5. Postmortem Interval (Succession Pattern). The different species of flies that occurred on the carrion during different stages of decomposition were identified. Fly succession pattern in both Kuala Terengganu and Masai were established. From the pattern, it gave an indication of the species that were present or absent in that location. Apart from that, the succession pattern gave a view of species present during different stages of decomposition. Thus, the elapsed time since death of a dead body was obtained by comparing the data. 
2.6. Meteorological and Temperature Data Collection. During sample collection, maggot mass temperature was recorded by inserting the thermometer into the center of the maggot mass. Soil temperature was taken directly under carrion and at a point 1 to $2 \mathrm{~m}$ from where the body was laid. Daily weather data that includes precipitation, relative humidity, daily minimum, and maximum temperatures were obtained from the nearest meteorological station at Sultan Mahmud Airport, Terengganu, and Senai International Airport, Johor.

2.7. Data Analysis. The degree of species composition or species diversity $\left(H^{\prime}\right)$ for each site was determined by using the Shannon Wiener Index. This index indicates the degree of species composition per unit area [20]:

$$
H^{\prime}=-\Sigma\left[\left(\frac{n i}{N}\right) \ln \left(\frac{n i}{N}\right)\right]
$$

where $H^{\prime}=$ Shannon-Wiener Index, $N=$ total individuals of population sampled, and $n i=$ total individuals belonging to the $i$ species.

Richness Index that has been used was Margalef's Index $(R)$. This index indicates the number of species in a sample or the abundance of the species per unit area [20]:

$$
R=\frac{S-1}{\ln (N)}
$$

where $R=$ Margalef Richness Index, $S=$ total of species, and $N=$ total of individuals sampled.

Homogeneity or pattern of distribution of species in relation to other species in a sampled per unit area was calculated using Evenness Index $(E)[20]$ :

$$
E=\frac{H^{\prime}}{H^{\prime} \max },
$$

where $E$ = Evenness Index, $H^{\prime}=$ Shannon-Wiener Diversity Index, and $H^{\prime} \max =$ Diversity Index observed to a maximum diversity.

Mann-Whitney $U$ test was used to compare the differences of the total abundance and number of species between the two study sites. Spearman correlation analysis was used to test the relationship of the temperature, relative humidity, rainfall, number of species, and abundance.

The analyses were conducted using SPSS 16.0 statistical software.

\section{Results and Discussion}

3.1. Dipteran Diversity. A total of 229 individuals from 11 species of Diptera belonging to six families were collected from mangrove areas in Kuala Terengganu and Masai (Table 1). Eight species were commonly found occurred in both mangrove areas. They were Chrysomya megacephala, C. rufifacies, Sarcophaga sp., Musca domestica, Homoneura tincta, and Cestrotus sp. Interestingly, two species were found endemic to mangrove areas: Homoneura tincta and Cestrotus sp.; both of them were from family Lauxaniidae. Fannia sp. was only found in Kuala Terengganu while Phaenicia sericata

\begin{tabular}{|c|c|c|}
\hline Mangrove(s) & Family & Species \\
\hline $\begin{array}{l}\text { Kuala } \\
\text { Terengganu, } \\
\text { Terengganu }\end{array}$ & Fannidae & Fannia sp. \\
\hline \multirow{2}{*}{ Masai, Johor } & Calliphoridae & Phaenicia sericata \\
\hline & Muscidae & Limnophora sp. \\
\hline \multirow{4}{*}{$\begin{array}{l}\text { Both } \\
\text { mangrove } \\
\text { areas }\end{array}$} & Calliphoridae & $\begin{array}{l}\text { Chrysomya megacephala } \\
\text { Chrysomya rufifacies }\end{array}$ \\
\hline & $\begin{array}{l}\text { Sarcophagidae } \\
\text { Muscidae }\end{array}$ & $\begin{array}{l}\text { Sarcophaga sp. } \\
\text { Musca domestica } \\
\text { Hydorotaea sp. }\end{array}$ \\
\hline & Lauxaniidae & $\begin{array}{l}\text { Homoneura tincta* } \\
\text { Cestrotus sp. }^{*}\end{array}$ \\
\hline & Phoridae & Megaselia sp. \\
\hline
\end{tabular}

TABLE 1: List of identified dipteran species (both adult and larvae) in Kuala Terengganu and Masai.

${ }^{*}$ Species found only in mangrove areas.

and Limnophora sp. were only found in Masai. The most dominant species found in both study sites were Chrysomya megacephala (31\% in Kuala Terengganu; 22\% in Masai) and C. rufifacies (27\% in Kuala Terengganu; $17 \%$ in Masai). The two least species found in Kuala Terengganu and Masai were Homoneura tincta and Cestrotus sp., both from family Lauxaniidae.

Basically, scores of all ecological indices were higher at Masai than at Kuala Terengganu. Based on Shannon Weiner Index, higher diversity of dipteran was scored at Masai with 2.056, while Kuala Terengganu scored 1.890. Similar trend could be observed for the Margalef Index, where the species richness at Masai and Kuala Terengganu was 1.900 and 1.686, respectively. Masai demonstrated higher value of Evenness Index which was 0.893 , followed by Kuala Terengganu with 0.860 .

However, there were no significant differences for number of species $(z=-0.817, P=0.414)$, number of family $(z=-1.200, P=0.230)$, and number of individuals $(z=$ $-0.487, P=0.626)$ between both study sites. Based on Spearman correlation analysis, mean ambient temperature significantly influenced the dipteran populations both in Kuala Terengganu and Masai $(r=0.488, P=0.008)$. Rainfall strongly influenced the number of species $(r=0.410, P=$ $0.030)$ and number of individuals $(r=-0.388, P=0.041)$ in both study sites. However, no correlation between relative humidity and dipteran diversity in both sites was detected.

3.2. Succession Pattern Based on Stages of Decomposition. Five different stages of decomposition were observed during the study: fresh, bloated, active decay, advanced decay, and skeletal, which were determined by the physical, weight, and body temperature changes of the carrion. Tables 2 and 3 show the succession patterns of dipteran species in Kuala Terengganu, Terengganu, and Masai, Johor, whereas Figures 1 and 2 show the decomposition stages for the carrions in both study areas. 
TABLE 2: Successional patterns of dipteran species in Kuala Terengganu mangrove area.

\begin{tabular}{|c|c|c|c|c|c|c|c|c|c|c|c|c|}
\hline \multirow{4}{*}{ Diptera species } & \multicolumn{12}{|c|}{ Day (PMI) } \\
\hline & 1 & 2 & 3 & 4 & 5 & 6 & 7 & 8 & 9 & 10 & 11 & 12 \\
\hline & \multicolumn{12}{|c|}{ Decomposition stages } \\
\hline & $\mathrm{F}$ & & BL & & \multicolumn{4}{|c|}{$\mathrm{ACD}$} & \multicolumn{3}{|c|}{$\mathrm{ADD}$} & DR \\
\hline $\begin{array}{l}\text { Chrysomya } \\
\text { megacephala }\end{array}$ & $*$ & $*$ & $*$ & * & & & & & & & & \\
\hline $\begin{array}{l}\text { Chrysomya } \\
\text { rufifacies }\end{array}$ & & $*$ & $*$ & $*$ & $*$ & $*$ & & & & & & \\
\hline Sarcophaga sp. & & $*$ & $*$ & * & & & & & & & & \\
\hline Hydrotaea sp. & & & & & * & $*$ & * & $*$ & $*$ & & & \\
\hline $\begin{array}{l}\text { Musca } \\
\text { domestica }\end{array}$ & & & & \# & \# & & & & & & & \\
\hline $\begin{array}{l}\text { Homoneura } \\
\text { tincta }\end{array}$ & & & $\#$ & \# & \# & & & & & & & \\
\hline Cestrotus sp. & & & & $\#$ & & $\#$ & & & & & & \\
\hline Megaselia sp. & & & & & & $*$ & & $*$ & $*$ & $*$ & $*$ & $*$ \\
\hline Fannia sp. & & & & & $\#$ & & $\#$ & \# & & $\#$ & & \\
\hline
\end{tabular}

Note: F: Fresh; BL: Bloated; ACD: Active decay stage; ADD: Advanced decay stage; DR: Dry remain.

*: Adult and immature stages present.

\#: Only adult individual present.

TABle 3: Successional patterns of dipteran species in Masai mangrove area.

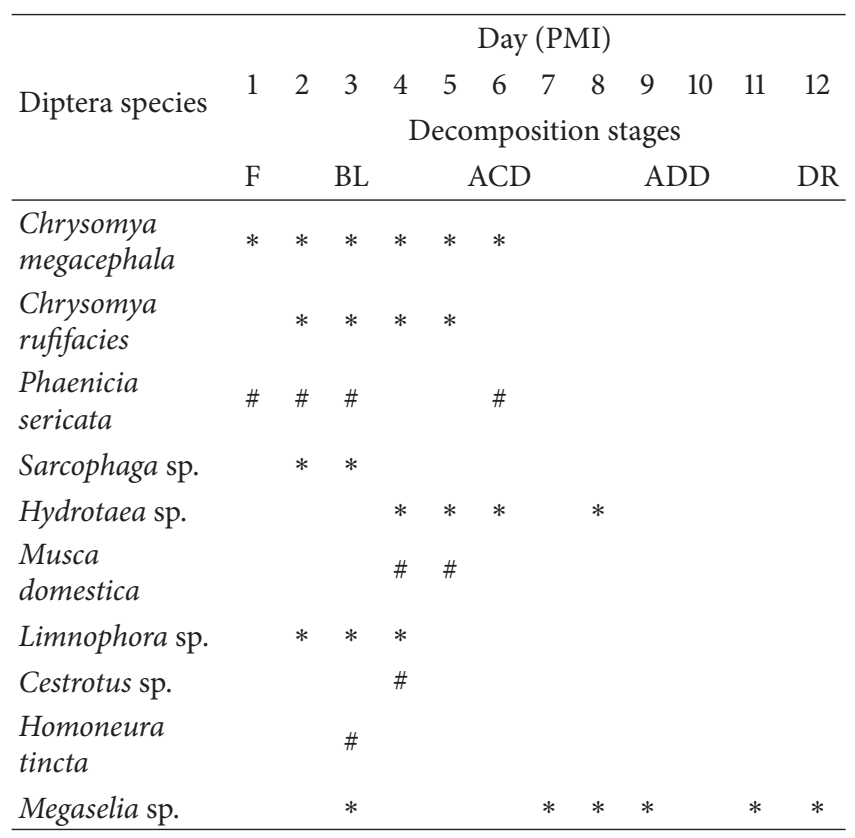

Note: F: Fresh; BL: Bloated; ACD: Active decay stage; ADD: Advanced decay stage; DR: Dry remain.

$*$ : Adult and immature stages present.

\#: Only adult individual present.

3.2.1. Fresh Stage. The first species coming to colonize carrion at Kuala Terengganu was a group of ants, identified as Oecophylla smaragdina which belongs to Formicidae. They invaded the neck's wound and the natural orifices of the body: the eyes, mouth, nose, anus, and genital. They were found actively fed on fluids from the body and also on adult flies by capturing them whilst the adult flies try to access the carrion. They also removed maggots from carrion at the later stages. Only a few of adults Calliphoridae which were C. megacephala were observed flying all over the cages and carcasses and in the surrounding grassy area. In contrast, the pioneer species visiting the carrion in Masai was Phaenicia sericata. By noon, ovipositing adults of Phaenicia sericata were found attracted to the suppurating neck wound and to the natural opening of the carrion such as nose and eyes. Limnophora sp. belonging to Muscidae was also observed colonized the carrion at Masai during the fresh stage.

3.2.2. Bloated Stage. Numerous adult flies were being observed to colonize the carrion. At Masai, Limnophora sp. found to be frequent the carrion as well as other blowflies. These small size species were found harbouring around the natural cavity such as nose and the mouth of the carrion. A few Sarcophaga sp. was seen to fly around the cages and grassy areas for Kuala Terengganu and Masai. Chrysomya megacephala and C. rufifacies were found colonized at this stage at both study sites. A few adult species, Homoneura tincta was observed at this stage. At Kuala Terengganu, Calliphoridae laid their eggs at the other body part, especially the genitals and under the fur of the body caused by the invasion of the ants around the wound. Hydrotaea sp., Musca domestica and Fannia sp. began to visit the carrion at the end of this stage. Overall the bloated stage lasted until day 3 for these study areas.

3.2.3. Active and Advanced Decay Stage. Adult Calliphoridae were abundant and the carcasses were literally bubbling with maggot activity. Hundreds of first, second, and third instar maggots shrouded each rabbit carcass. As the result of maggot feeding, the head area of many of the carcasses had deteriorated, leaving detached ears. At Kuala Terengganu, species Hydrotaea sp., Megaselia sp., and Fannia sp. colonized at this stage. Whereas at Masai, C. megacephala, Phaenicia sericata, Hydrotaea sp., and Megaselia sp. were observed frequent the carrion at this stage. Less number of Cestrotus sp. were spotted at this stage at both study sites. The carcass in Kuala Terengganu seemed to active decay more gradually till day 4 whereas this stage continued till day 5 for Masai. After 6 to 9 days of the rabbit's death in both sites, the weight of the carrion dropped to $41.9 \%$. Besides the absence of odour and the removal of a great part of the soft tissues, no larva was observed. In contrast, puparium was seen underneath the carrion and in between the carrion's bones.

3.2.4. Skeletal Stage. On day 10 at both sites, only remains of dried skin and bones were left which characterized the skeletal stage. The carrion's weight decreased consistently but not much throughout the skeletal stage where by the end of this study, on day $14,12.8 \%$ was left of the carrion. Small numbers of larvae were found concentrated underneath the carrion and where small amounts of soft tissues were left in 


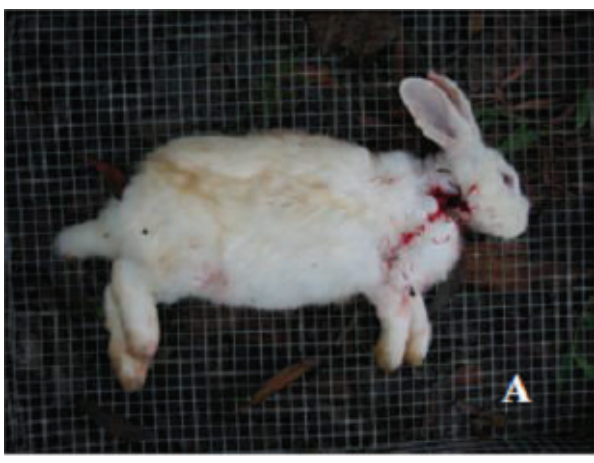

(a)

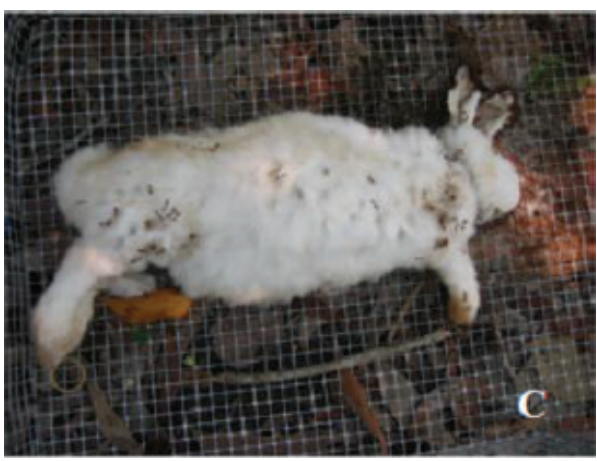

(c)

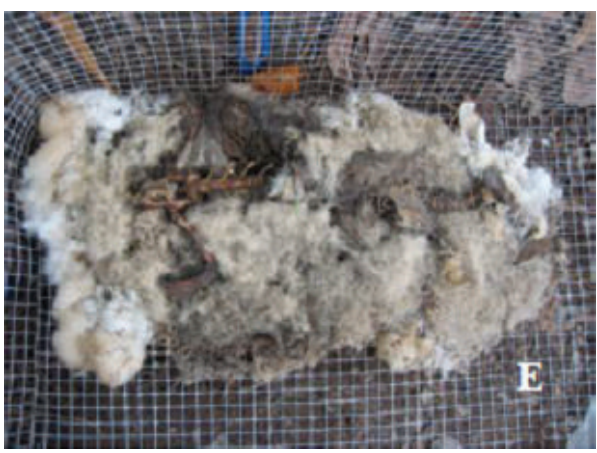

(e)

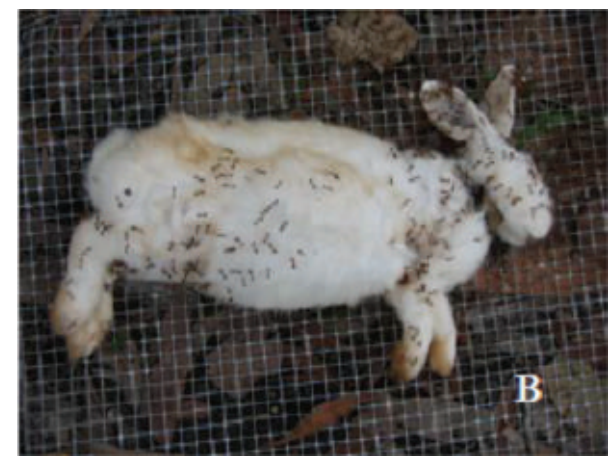

(b)

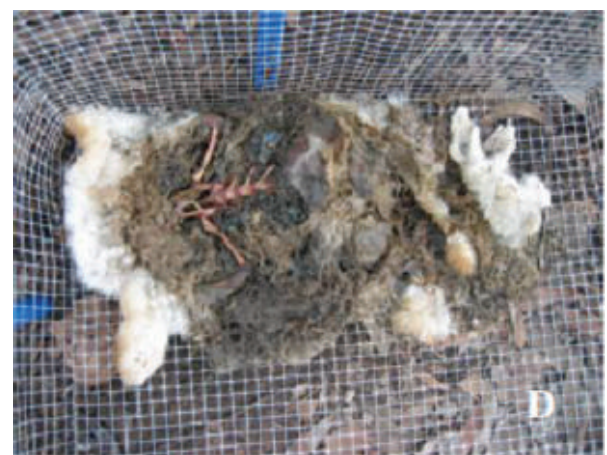

(d)

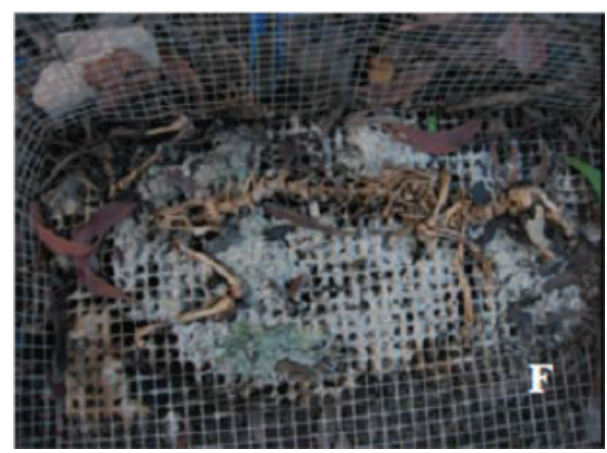

(f)

FIGURE 1: Decomposition stages of rabbit carrion in mangrove area of Kuala Terengganu, Terengganu. (Note: (a) fresh stage, (b) bloated stage, (c) active decay stage, ((d) and (e)) advanced decay stage, (f) skeletal stage).

the stomach. No adult flies were observed in this stage. Both carrions in both sites reached the skeletal stage by day 10 .

In present study, all species identified have been commonly documented to be forensically important except for Homoneura tincta and Cestrotus sp. from family Lauxaniidae. Homoneura tincta is small, robust fly with orange colouring, whereas Cestrotus sp. is black colouring with the wings being opaque and spotted. These lauxaniid flies often occur in the mangrove swamps [21].

Among all the meteorological factors, ambient temperature and rainfall were identified to be the strongest factors affecting dipteran succession and development. The duration of the decay process depended on climatic conditions. The biomass loss occurred very fast during the fresh to active decay stages (from day 1 to 6 ) at Kuala Terengganu mangrove area, while the biomass loss occurred moderately from the fresh to active decay stages (from day 1 to 5) at Masai mangrove area. Only approximately $20 \%$ of total biomass remained at Kuala Terengganu but the biomass loss of the carrion at Masai still remained approximately $50 \%$ (Figure 3 ). Carrion in Masai with lower temperature and rainy season retarded insect succession and prolonged the decomposition stages. Carrion in Kuala Terengganu with higher temperature speeded up succession and decayed at faster rate. The higher temperature of the corpse due to maggot activity also leads to quick decay.

The rate of decomposition is exceptionally faster than that of other study which took a minimum of 30 days or more to reach the same stage. This situation may be explained by the particular conditions of warmer temperatures in this 


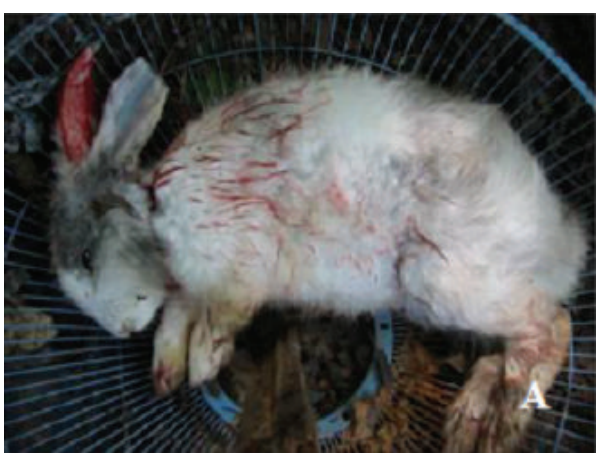

(a)

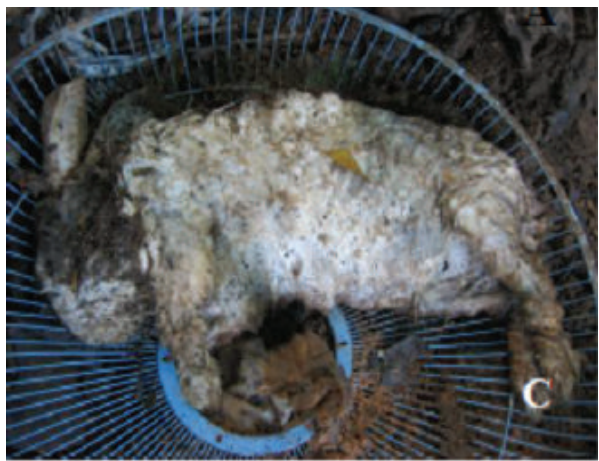

(c)

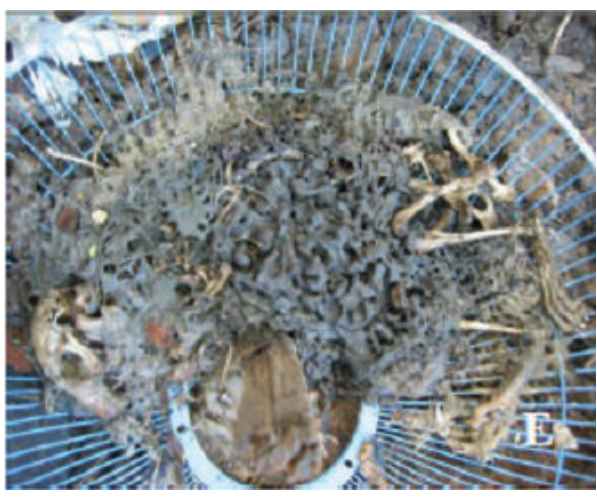

(e)

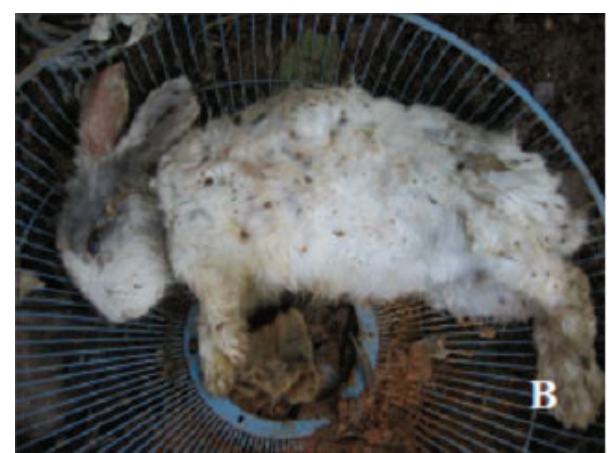

(b)

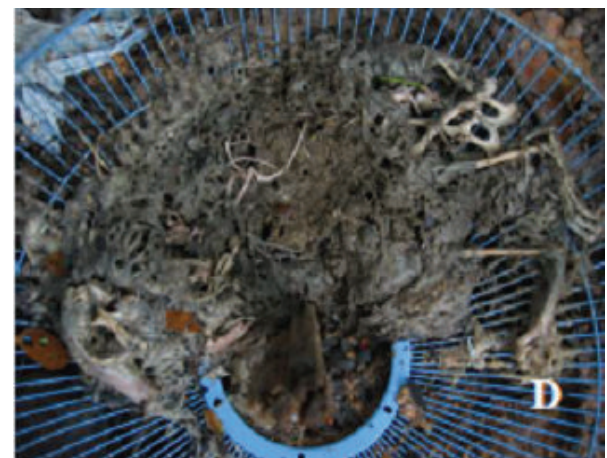

(d)

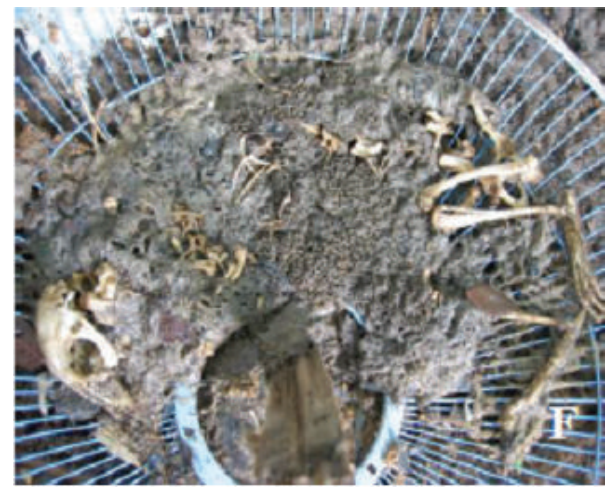

(f)

FIGURE 2: Decomposition stages of rabbit carrion in mangrove area of Masai, Johor. (Note: (a) fresh stage, (b) bloated stage, (c) active decay stage, ((d) and (e)) advanced decay stage, (f) skeletal stage).

study (mean temperatures of $27.5^{\circ} \mathrm{C}$ in Masai; $28.2^{\circ} \mathrm{C}$ in Kuala Terengganu) compared with the other reports (mean temperatures of $18.0^{\circ} \mathrm{C}$ to $24.0^{\circ} \mathrm{C}$ ). In Kuala Terengganu, warmer temperatures and fever precipitation speeded up the succession by accelerating the development and activity of dipterous larvae which in turn produced faster degradation of corpse. Payne [22] found that high temperatures during warmer days intensified insect activity, resulting in a rapid depletion of the carrion. In Masai, the low temperatures retarded the development and activity of dipterous larvae; hence speed of succession was slowed, as was degradation of corpse. The environment is usually the main factor in determining the postmortem interval since the ambient temperature has a direct influence on both the putrefaction processes and insect activity. Cold temperatures slow down organic matter decay, inhibiting bacterial proliferation and preserving corpse tissues longer. Warm temperatures speed up the decomposition process increasing bacterial proliferation and also the number and type of carrion insects [23].

In addition, while at the active decay decomposition stages, there were heavy rainfalls which caused the formation of grayish adipocere (grave wax) at the abdomen. Rains inhibit the decomposition. Blow flies are typically sensitive to moisture levels. When moisture is too high, blow fly larvae will leave a carcass and have been noted to cease larval development [22]. This was prolonged the decomposition stages of the carrion [5]. The oviposition of species within the insect order Diptera (flies) is negligible at temperatures 


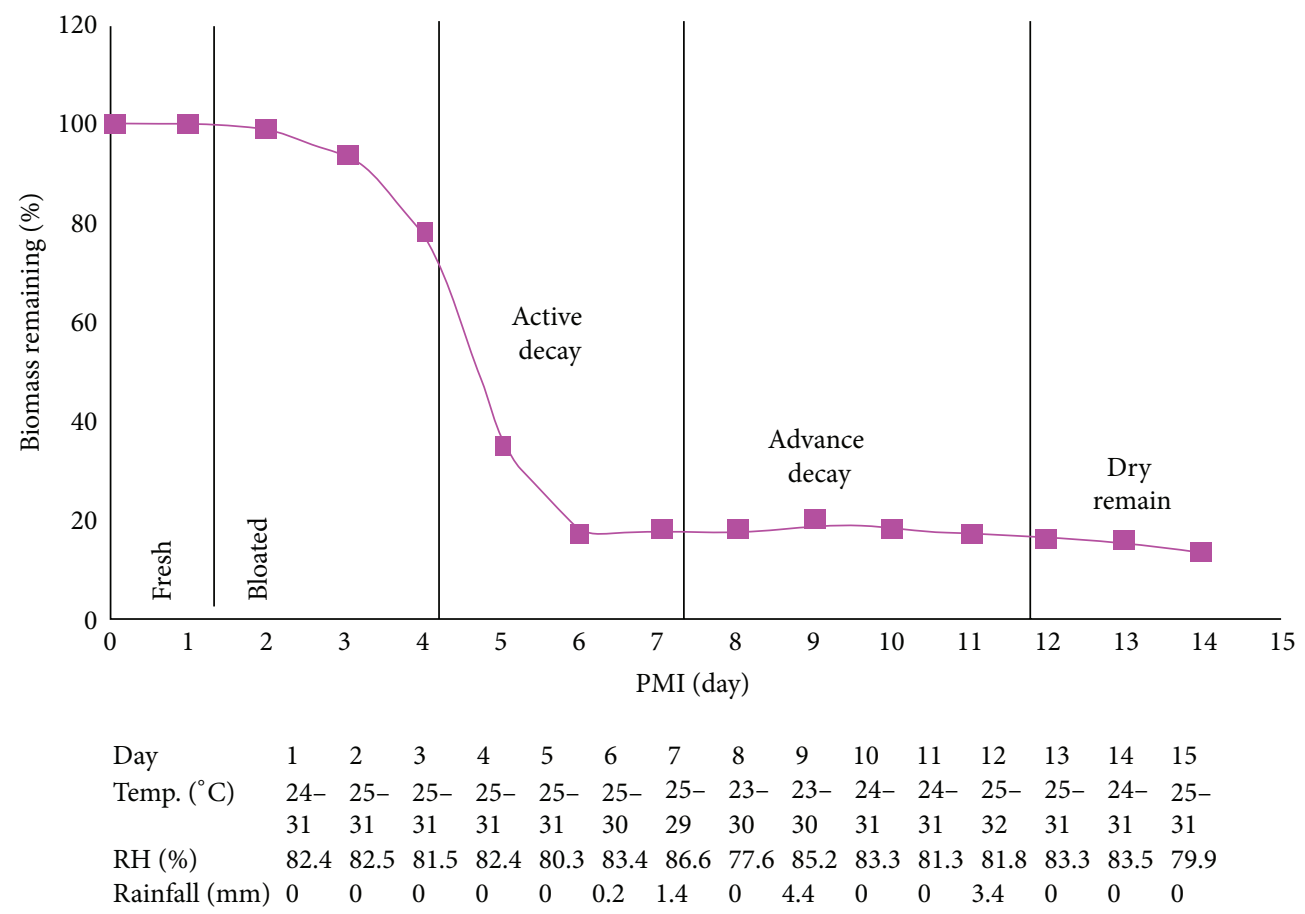

(a)

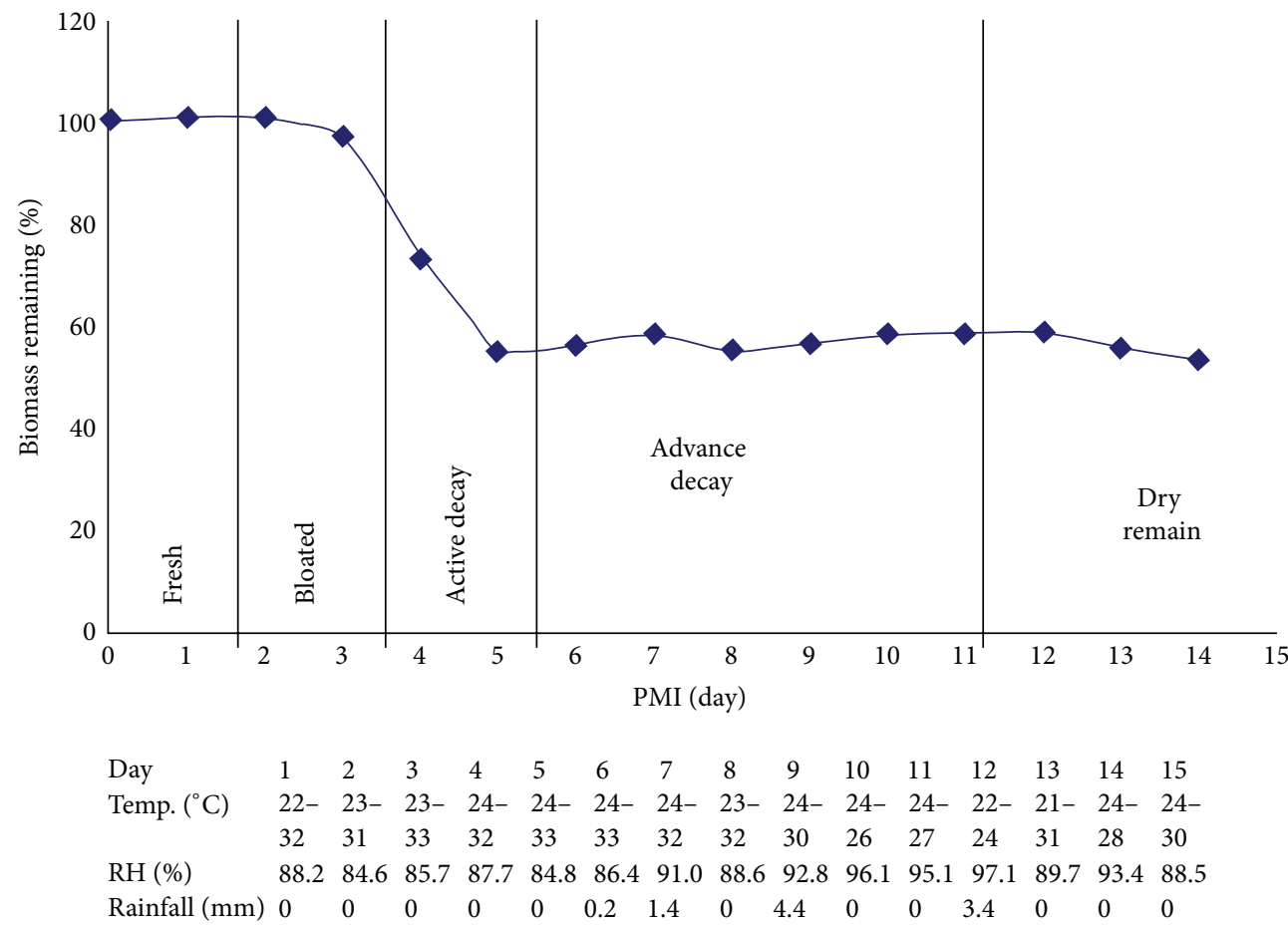

(b)

FIgURE 3: Percentage of biomass loss of the carrion with the postmortem interval (PMI) in relation to ambient mean temperature, humidity, and rainfall at (a) Kuala Terengganu and (b) Masai mangrove areas.

below $10^{\circ} \mathrm{C}$. This is due to the poikilothermic (cold-blooded) nature of insects. Therefore, it can be inferred that the decomposition process will also be considerably slower in the monsoon season due to the lower average temperatures. The developmental speed of the resulting larvae was also decreased due to the low temperatures again lengthening the decomposition time [14].

Some insects shun light, others prefer it; it thus follows that deep shade will affect the species of insects on a carrion. Chrysomya (Diptera: Calliphoridae) preferred shady 
conditions while Phenicia (Diptera: Calliphoridae) and Sarcophaga (Diptera: Sarcophagidae) prefer sunlight. Apparently, shaded area of both sites were mostly preferred and attracted by Calliphoridae. This was true when we observed the carrions in this two study sites with the shady condition of the mangrove areas contributed by dense canopy of trees attracting a lot of Chrysomya. Phaenicia sericata, although it visits the carrion at Masai, showed less number. According to Cragg [24], the blowfly Phaenicia sericata does not usually oviposit on carcasses with a surface temperature below $30^{\circ} \mathrm{C}$. Therefore, if eggs of this species are found on a human corpse lying in a place that is in shadow during the entire day, the finding may be interpreted as indicating that the corpse has been removed from an area in which there was sunshine earlier [25].

Besides meteorological factors, smaller carrion biomass available will induce shorter postmortem interval or faster decomposition rates. Here, rabbits weighing around one kilogram were used compared with heavier carrions in other studies. Micozzi [26] found that the composition of insect community did not show significant differences between human and pig but the amount of carrion available strongly influenced the postmortem interval.

This study shows that diversity of species, type of species, number of individuals, life stages present, and the number of individuals of each life stage can all be derived from succession studies in different localities. Information gained from this study is hoped to provide the knowledge of local carrion fauna which provides a complimentary approach to postmortem estimation particularly in mangrove area of tropical regions.

\section{Conflict of Interests}

The authors declare that there is no conflict of interests with any commercial identities mentioned in this paper.

\section{Acknowledgments}

The authors would like to thank Mr. Muhammad bin Embong, for assistance during field work and in the laboratory, and the Department of Biological Sciences, Faculty of Science \& Technology, Universiti Malaysia Terengganu for the financial support for this study.

\section{References}

[1] J. H. Skevington and P. T. Dang, "Exploring the diversity of flies (Diptera)," Biodiversity, vol. 3, no. 4, pp. 20-21, 2002.

[2] K. L. Tabor, R. D. Fell, and C. C. Brewster, "Insect fauna visiting carrion in Southwest Virginia," Forensic Science International, vol. 150, no. 1, pp. 73-80, 2005.

[3] R. D. Hall, "Introduction: perceptions and status of forensic entomology," in Forensic Entomology: The Utility of Arthropods in Legal Investigations, J. H. Byrd and J. L. Castner, Eds., pp. 1-15, CRC Press, Boca Raton, Fla, USA, 2001.

[4] H. B. Jason and L. C. James, Forensic Entomology: The Utility of Arthropods in Legal Investigations, CRC Press, London, UK, 2001.
[5] G. S. Anderson, "Minimum and maximum development rates of some forensically important Calliphoridae (Diptera)," Journal of Forensic Sciences, vol. 45, no. 4, pp. 824-832, 2000.

[6] E. P. Catts and M. L. Goff, "Forensic entomology in criminal investigations," Annual Review of Entomology, vol. 37, no. 1, pp. 253-272, 1992.

[7] H. L. Lee, "Recovery of forensically important entomological specimens from human cadavers in Malaysia-an update," The Malaysian Journal of Pathology, vol. 11, pp. 33-36, 1989.

[8] H. L. Lee, "Forensically important fly maggots recovered from human cadavers in Malaysia," Tropical Biomedicine, vol. 13, pp. 93-94, 1996.

[9] H. L. Lee and T. M. Marzuki, "Preliminary observations of the occurrence of arthropods on carrion and its application to forensic entomology in Malaysia," Tropical Biomedicine, vol. 10, pp. 5-8, 1993.

[10] B. Omar, A. M. Mohamed, S. Sulaiman, and P. Oothuman, "Dipteran succession in monkey carion at a rubber tree plantation in Malaysia," Tropical Biomedicine, vol. 11, pp. 77-82, 1994.

[11] P. B. Tomlinson, The Botany of Mangroves, Cambridge University Press, London, UK, 1986.

[12] L. M. L. Carvalho, P. J. Thyssen, M. L. Goff, and A. X. Linhares, "Observations on the succession patterns of necrophagous insects on a pig carcass in an urban area of Southeastern Brazil," Anil Aggrawal's Internet Journal of Forensic Medicine and Toxicology, vol. 5, no. 1, pp. 33-39, 2004.

[13] M. L. Goff, A Fly for the Prosecution: How Insect Evidence Helps Solve Crimes, Harvard University Press, Cambridge, Mass, USA, 2000.

[14] J. H. Byrd and J. L. Castner, Forensic Entomology: The Utility of Arthropods in Legal Investigations, CRC Press, New York, NY, USA, 2001.

[15] C. J. Stojanovish, H. D. Pratt, and E. E. Bennington, Fly Larvae: Key to Some Species of Public Health Importance, U.S. Department of Health, Education and Welfare, Atlanta, Ga, USA, 1962.

[16] J. M. Seago, Fly Larvae: Pictorial Key to Common Species, U.S. Department of Health, Education and Welfare, Atlanta, Ga, USA, 1953.

[17] J. F. Wallman, "A key to the adults of species of blowflies in southern Australia known or suspected to breed in carrion," Medical and Veterinary Entomology, vol. 15, no. 4, pp. 433-437, 2001.

[18] H. G. Scott and M. E. Borom, Domestic Flies: Pictorial Key to Common Species, U.S. Department of Health, Education and Welfare, Atlanta, Ga, USA, 1962.

[19] H. R. Dodge, Diptera: Pictorial Key to Principal Families of Public Health Importance, U.S. Department of Health, Education and Welfare, Atlanta, Ga, USA, 1953.

[20] J. L. Metcalfe, "Biological water quality assessment of running waters based on macroinvertebrate communities: history and present status in Europe," Environmental Pollution, vol. 60, no. 1-2, pp. 101-139, 1989.

[21] L. Papp, "Dipterous guilds of small-sized feeding sources in forests of Hungary," Acta Zoologica Academiae Scientiarum Hungaricae, vol. 48, supplement 1, pp. 197-213, 2002.

[22] J. A. Payne, "A summer carrion study of the baby pig sus scrofa Linnaeus," Ecology, vol. 46, no. 5, pp. 592-602, 1965.

[23] C. P. Campobasso and F. Introna, "The forensic entomologist in the context of the forensic pathologist's role," Forensic Science International, vol. 120, no. 1-2, pp. 132-139, 2001. 
[24] J. B. Cragg, "The olfactory behaviour of Lucilia species (Diptera) under natural conditions," Annals of Applied Biology, vol. 44, pp. 467-477, 1956.

[25] B. S. Shean, L. Messinger, and M. Papworth, "Observations of differential decomposition on sun exposed v. shaded pig carrion in coastal Washington state," Journal of Forensic Sciences, vol. 38, no. 4, pp. 938-949, 1993.

[26] M. S. Micozzi, "Postmortem change in human and animal remains," American Journal of Human Biology, vol. 4, pp. 695696, 1991. 

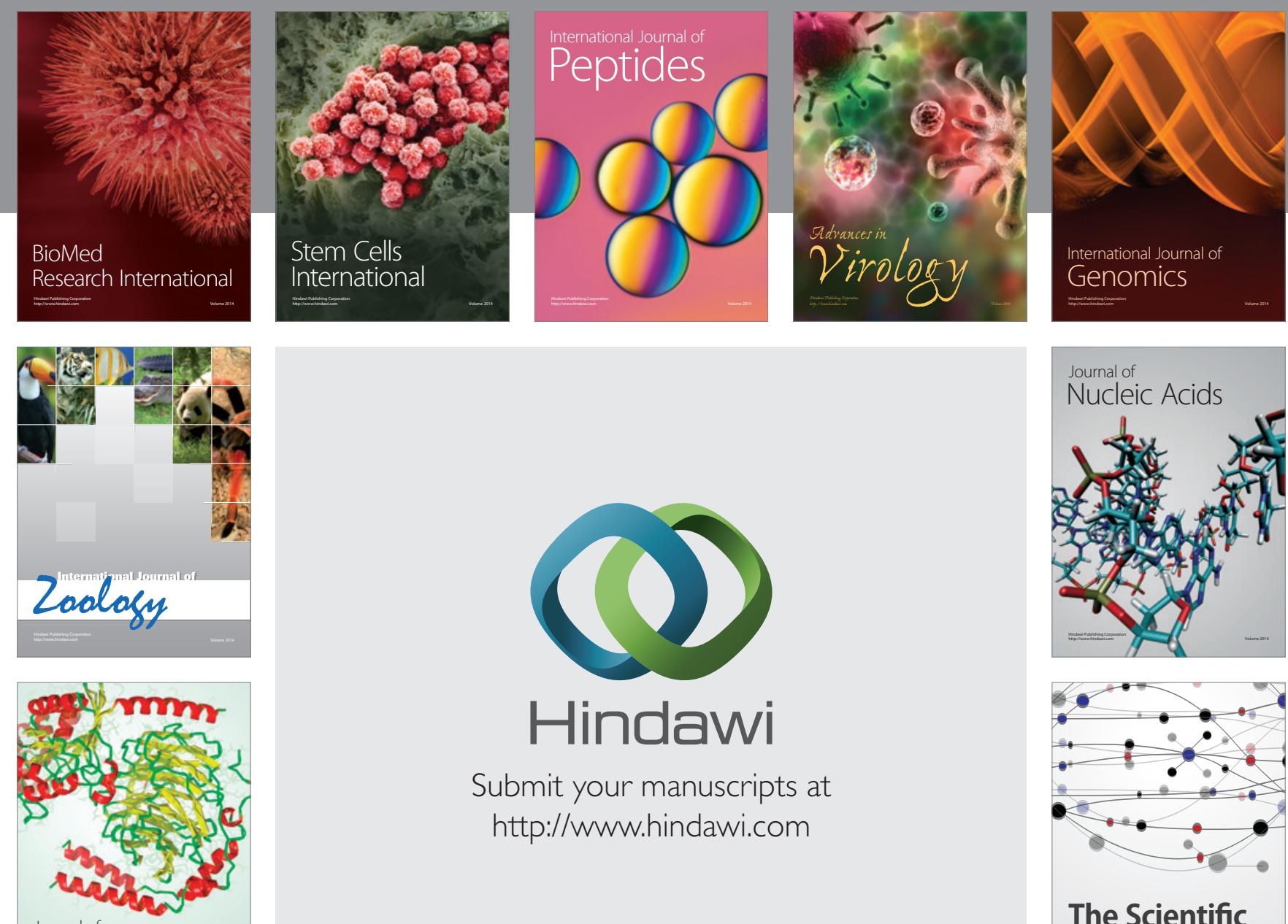

Submit your manuscripts at

http://www.hindawi.com

Journal of
Signal Transduction
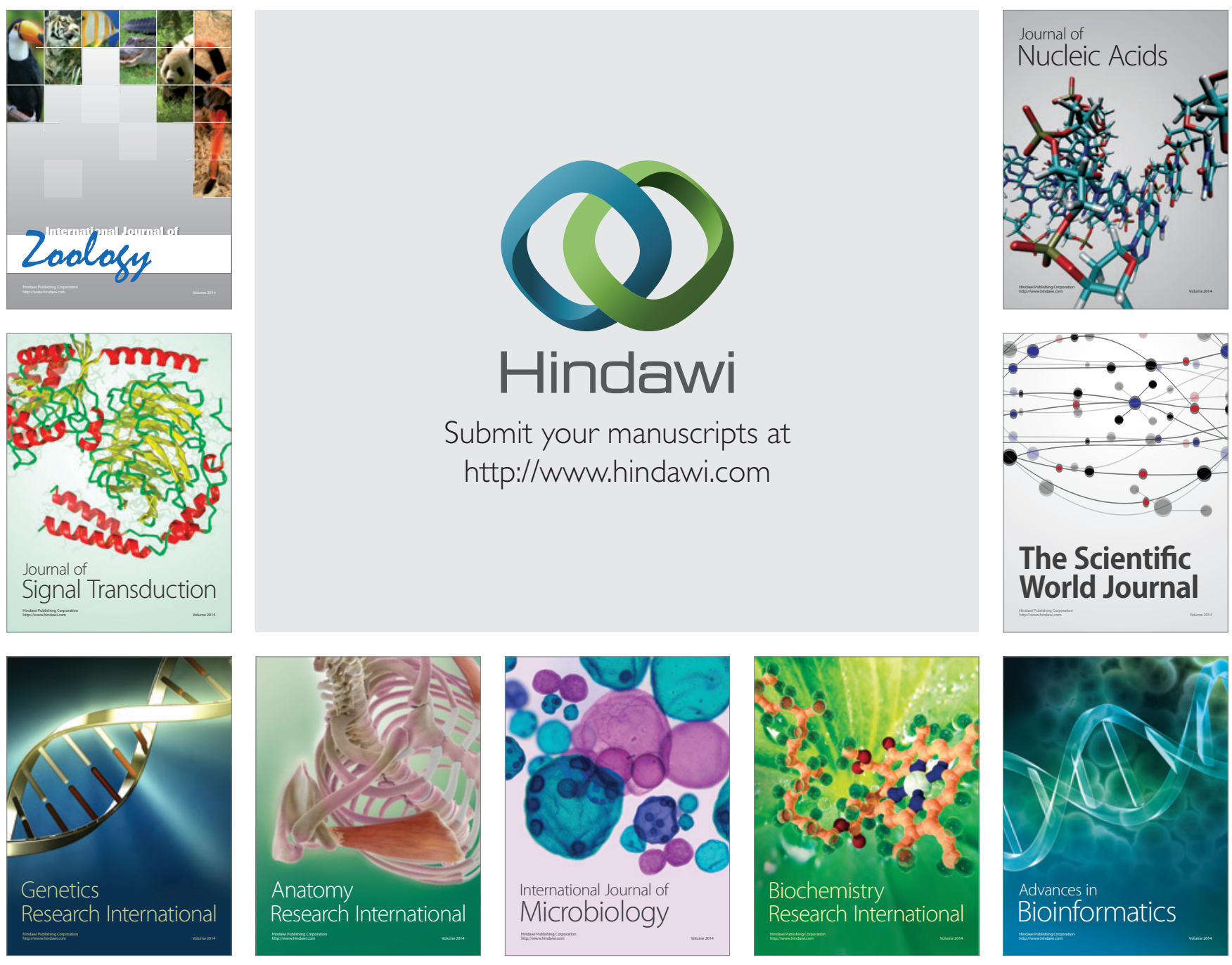

The Scientific World Journal
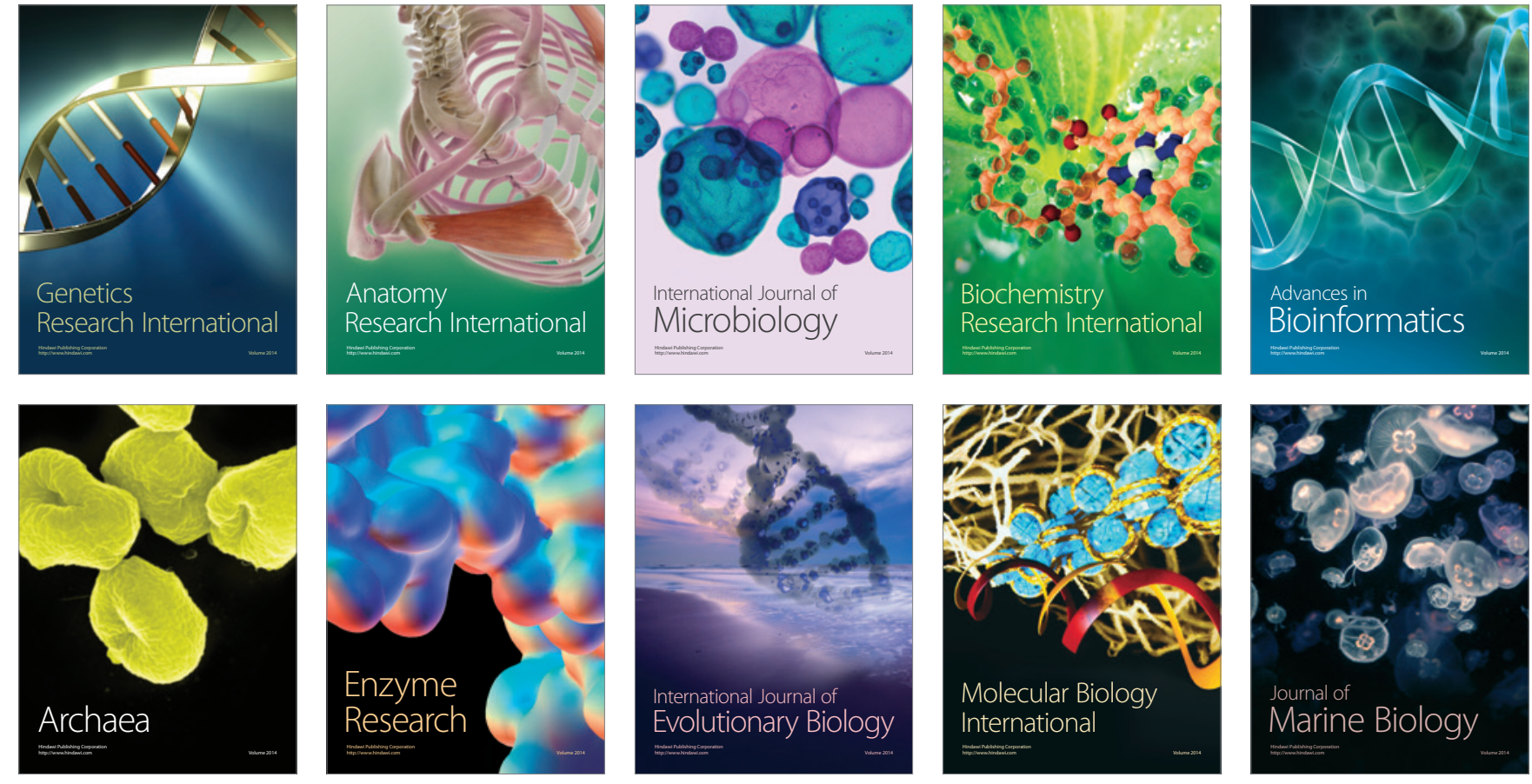